\title{
The Effects of Loading Rate and Duration on the Axial Behavior of Low-Strength and Medium-Strength Noncircular Concrete Members Confined by Fiber-Reinforced Polymer Sheets
}

\section{Cem Demir *, Aygul Kucukkapili, Duygu Doyrangol and Alper Ilki}

Department of Civil Engineering, Istanbul Technical University, Ayazaga, Sariyer, Istanbul 34469, Turkey; E-Mails: akucukkapili@gmail.com (A.K.); ddoyrangol@hotmail.com (D.D.); ailki@itu.edu.tr (A.I.)

* Author to whom correspondence should be addressed; E-Mail: demirce @itu.edu.tr;

Tel.: +90-505-346-0153; Fax: +90-212-285-6106.

Received: 8 May 2014; in revised form: 28 May 2014 / Accepted: 29 May 2014 /

Published: 6 June 2014

\begin{abstract}
In this study, 36 concrete specimens with square cross-sections and different concrete qualities were tested either under uniaxial compression at different loading rates or subjected to sustained uniaxial stresses after externally jacketing with carbon fiber-reinforced polymer (CFRP) sheets. The main test parameters were the loading rate and the applied sustained stress level. Among these parameters, the loading rate varied in the range of 0.0002 and 0.04 strain/min. In the case of short-term creep tests under sustained loads, three stress levels (between $0.73 f^{\prime}$ cc and $0.90 f^{\prime}{ }_{\text {cc }}$ or $2.76 f^{\prime}{ }_{\text {cc }}$ and $3.37 f^{\prime}{ }_{c c}$ ) for low-strength and four stress levels (between $0.69 f^{\prime}{ }_{\mathrm{cc}}$ and $0.92 f_{\mathrm{cc}}^{\prime}$ or $0.89 f_{\text {co }}^{\prime}$ and $1.20 f^{\prime}{ }_{\mathrm{co}}$ ) for medium-strength prisms were applied. The test results showed that the stress-strain behavior of CFRP-confined concrete was affected by the change in loading rate, and external CFRP confinement enhanced the creep performance of concrete significantly. For low-strength concrete specimens, higher strain rates did not bring higher strength values; however, an increase in strength was obvious for medium-strength prisms. On the other hand, for both concrete qualities, the specimens loaded at slower strain rates exhibited better deformability. None of the specimens of the medium-strength concrete failed during the short-term creep tests; however, three of the low-strength concrete prisms failed during the tests. The results of residual strength tests showed that sustained loading did not cause a strength or ultimate deformation capacity loss, but affected the residual strain capacities.
\end{abstract}


Keywords: concrete; confinement; creep; fiber-reinforced polymer; loading rate; low strength; medium strength; strain rate; sustained load

\section{Introduction}

In the last two decades, several experimental and analytical studies that investigated the uniaxial compression behavior of fiber-reinforced polymer (FRP)-confined concrete have been performed, and extensive data on the stress-strain behavior of concrete have been collected [1]. These studies included several tests performed on different cross-section shapes, concrete qualities and FRP wrapping configurations [2-8]. However, in the majority of the experiments, the loading rate applied during the uniaxial loading was kept constant. Furthermore, generally, the loading rates vary between 0.0006 and $0.002 \mathrm{strain} / \mathrm{min}$. This range of the loading rate can be accepted to be in the range of static loading. In fact, structures are exposed to much higher strain rates during seismic actions [9]. Therefore, the stress-strain behavior of FRP-confined concrete should be investigated under higher strain rates, in order to have a better perception of earthquake performance. One of a few studies has been carried out by Demir et al. [10] as a preliminary phase of the tests presented in this paper. Demir et al. [10] performed uniaxial compression tests with strain rates varying between 0.0002 and 0.04 strain/min. The specimens were CFRP-confined cylinders cast with $31.2 \mathrm{MPa}$ medium-strength concrete. The test results pointed to an increase in compressive strength and the elasticity modulus for higher strain rates (i.e., $0.04 \mathrm{strain} / \mathrm{min}$ ) and an increase in the deformation capacity for lower strain rates (i.e., 0.0002 strain/min). Tests performed by Zhang et al. [11] on medium-strength concrete prisms, under four different levels of strain rates (varying between 0.0006 and 0.6 strain/min), gave similar results, with emphasis on the slight increase of Poisson's ratio with increased strain rates.

It is well known that in many existing structures, particularly in buildings constructed in developing countries, there is a lack of engineered design procedures. Even the engineered ones frequently suffer from low concrete quality, due to construction malpractices. In the case of Turkey, the average concrete compressive strength can be assumed to be around $10 \mathrm{MPa}$ for buildings constructed before the 1990s. Consequently, when the actual concrete strength used during the construction is lower than that foreseen at the structural design phase, the sustained axial stresses of columns may be remarkably high (70\% 90\% of column axial capacity). These high axial stresses sometimes cause the collapse of columns or the overall structure, due to creep effects on concrete. Views of columns from a building in Diyarbakir, Turkey, which were recently damaged under sustained loads, are shown in Figure 1. Along with the low concrete quality, reinforcement detailing problems and inadequate utilization of transverse reinforcement negatively affect the load bearing capacity and ductility performance. The service life of such structures can be enhanced through external jacketing of columns with FRP sheets. However, although a significant number of experimental studies exist for investigation of the behavior of fiber-reinforced polymer (FRP)-confined concrete members under short-term loading, a limited number of studies has considered the behavior under sustained axial loads [10,12-18]. In the preliminary phase of this study, Demir et al. [10] tested CFRP-confined medium strength cylinders under $50 \mathrm{~h}$ for four different sustained stress levels that varied between $52 \%$ and $85 \%$ of the confined concrete strength $\left(f_{\text {cc }}^{\prime}\right)$ and carried out 
predictions for the lifetimes of specimens. Since these specimens had circular cross-sections, the confinement pressure distributions were uniform. Accordingly, despite the high sustained loads, FRP confinement proved to be an effective measure against potential creep failure. Moreover, residual capacity tests after sustained loading showed that there was not any deterioration in strength and deformability.

The aim of this paper is to study the effects of loading rate and short-term creep on the stress-strain relationships of low- and medium-strength concrete prisms with square cross-sections. For this purpose, the results of short-term monotonic loading tests at different loading rates, short-term creep tests and residual strength tests performed on CFRP confined square specimens are presented. Additionally, the general results are compared with a preliminary study performed on medium-strength cylinders [10]. Seventeen square cross-sectioned specimens with low-strength concrete (6.8 MPa unconfined concrete strength) and nineteen square cross-sectioned specimens with medium-strength concrete (31.2 MPa unconfined concrete strength) were tested under uniaxial compression. Three specimens with medium-strength concrete and two specimens with low-strength concrete were chosen as reference unconfined specimens. Additionally, one low-strength concrete specimen was left unconfined and tested under sustained loads. The rest of the specimens were wrapped by three plies of CFRP sheets. The applied loading rate, sustained stress/strength ratio and concrete quality are the main parameters of this study. The originality of the study stems from the non-circular cross-section shape and low-strength concrete used for the construction of the specimens. It should be noted that the initial results of this study for the short-term creep behavior of low-strength specimens have been presented in Demir et al. [19].

Figure 1. Columns damaged under sustained loads.
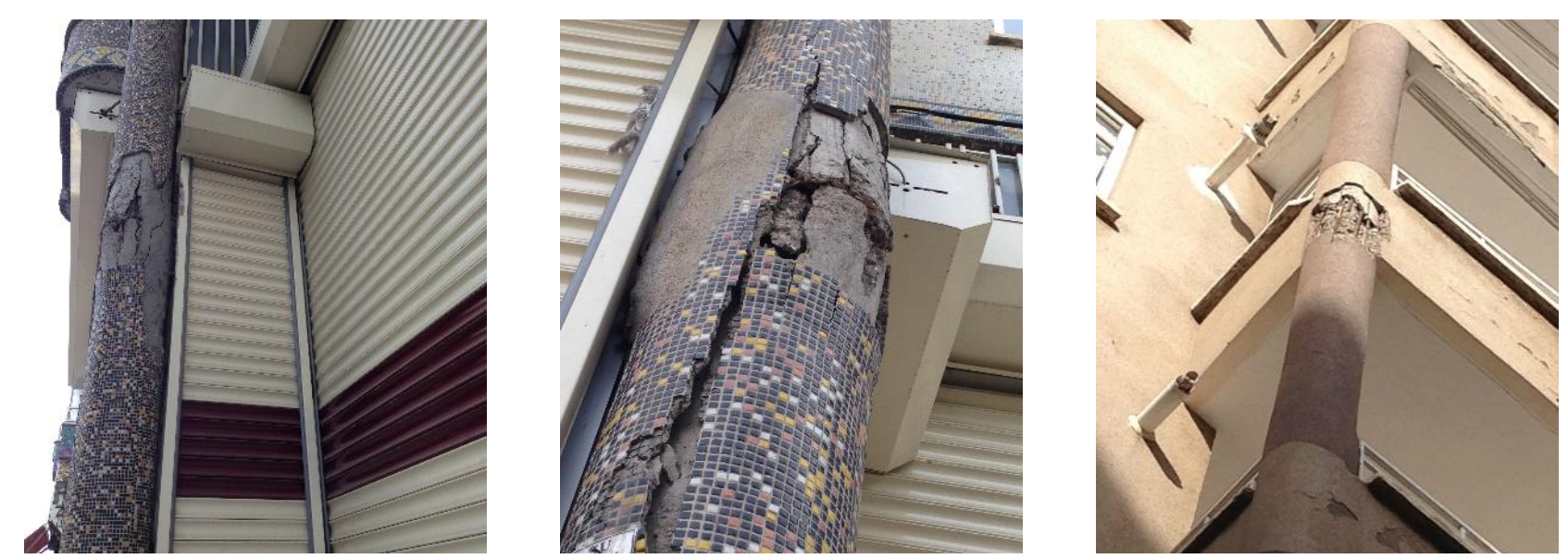

\section{Experimental Program}

\subsection{Specimen Preparation}

Thirty-six square cross-sectioned prism specimens with dimensions of $150 \mathrm{~mm} \times 150 \mathrm{~mm} \times 300 \mathrm{~mm}$ were cast using both medium-strength and low-strength concrete. The cement, water, sand, gravel and crushed stone weights used in the unit volume of the medium-strength and low-strength concrete mixes were $375,140,490,1025,355\left(\mathrm{~kg} / \mathrm{m}^{3}\right)$ and 197, 231, 563, 852, $272\left(\mathrm{~kg} / \mathrm{m}^{3}\right)$, respectively. Portland cement and a maximum aggregate size of $15 \mathrm{~mm}$ were used in both of the mixtures. The corners of all 
specimens were rounded to a $15-\mathrm{mm}$ radius. Sixteen of the specimens from the medium-strength concrete group and fourteen of the specimens from the low-strength concrete group were wrapped in the transverse direction with three plies of CFRP sheets (Figure 2a). CFRP sheets were bonded onto the concrete surface by using a two-component epoxy adhesive, and a 150-mm overlap was formed at the end of the wrap. While wrapping the CFRP sheets, a 10-mm spacing was left from the top and bottom ends of the specimens to avoid the direct axial loading of the sheets. Finally, all specimens were capped with sulfur and graphite. CFRP sheets with a tensile strength of $3800 \mathrm{MPa}$ and a Young's modulus of $240,000 \mathrm{MPa}$ were used for wrapping, as provided by the manufacturer. The ultimate elongation and thickness of one ply of the CFRP sheet was $1.55 \%$ and $0.117 \mathrm{~mm}$, respectively.

Figure 2. (a) Carbon fiber-reinforced polymer (CFRP) wrapping of concrete prisms. (b) Test setup.

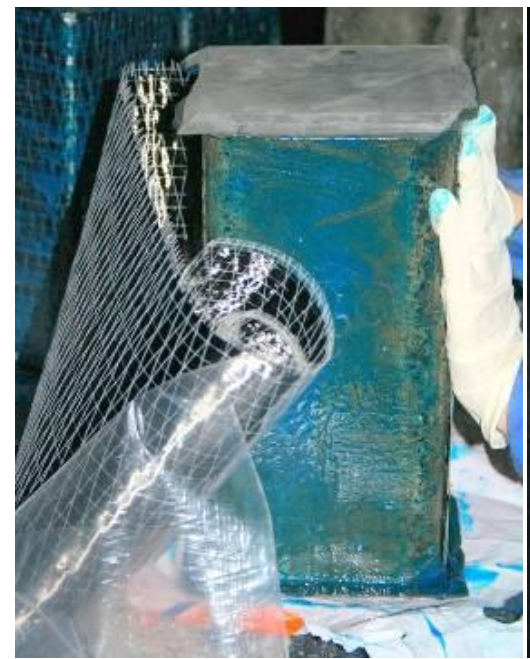

(a)

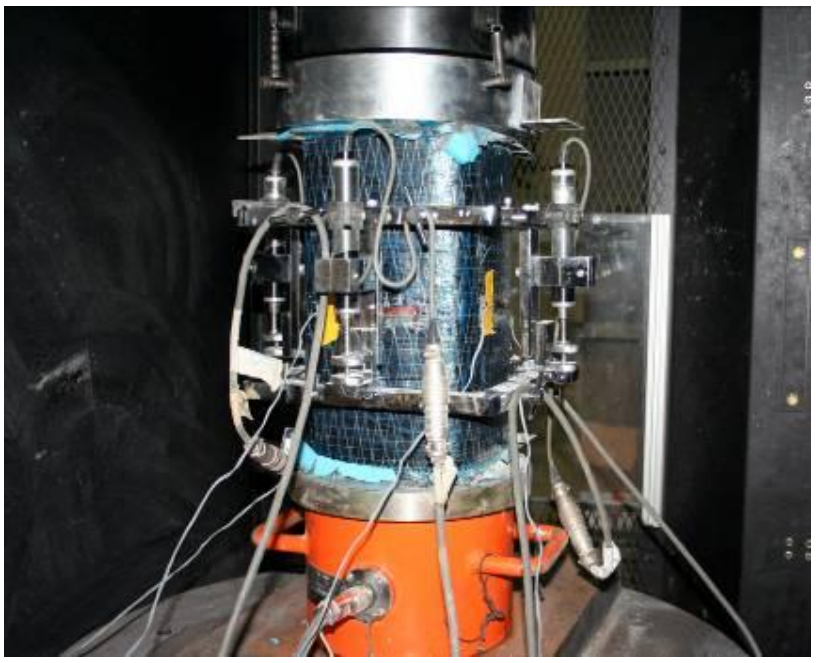

(b)

The nomenclature of the short-term monotonic loading test specimens depends on the utilized concrete strength ( $\mathrm{L}$ for low- and $\mathrm{M}$ for medium-strength concrete), the type of applied load (M: monotonic), the number of CFRP plies (0 or 3 plies), the loading rate (L0, L1, L2 or L3) and the specimen sequence code (A, B or C). For example, LM3L2A represents the first low-strength concrete specimen, which is tested under monotonic loading, confined with 3 plies of CFRP and loaded with a loading rate of $\mathrm{L} 2$, which is 0.002 strain/min. In the case of short-term sustained loading tests, the specimens were named as LSR or MSR (L for low-strength and M for medium-strength concrete), which were followed by the specimen sequence code (i.e., LSRA). The test matrix of the study is presented in Table 1. 
Table 1. Tested specimens and investigated parameters. Specimen nomenclature: L, low-strength concrete; M, medium-strength concrete; the number of carbon fiber-reinforced polymer (CFRP) plies (0 or 3 plies); the loading rate (L0, L1, L2 or L3); and the specimen sequence code (A, B or $\mathrm{C})$.

\begin{tabular}{|c|c|c|c|c|c|}
\hline $\begin{array}{l}\text { Concrete } \\
\text { Strength }\end{array}$ & Test Type & Specimens & $\begin{array}{c}\text { Loading Rate } \\
\text { (strain/min) }\end{array}$ & $\begin{array}{c}\text { Sustained Load } \\
\text { Duration (h) }\end{array}$ & $\begin{array}{c}\text { Sustained Axial } \\
\text { Stress Level }^{1} \\
\end{array}$ \\
\hline \multirow{9}{*}{ Low Strength } & \multirow{5}{*}{ Loading Rate } & LM0L2A, LM0L2B & 0.002 & - & - \\
\hline & & LM3L0A, LM3L0B & 0.04 & - & - \\
\hline & & LM3L1A, LM3L1B & 0.02 & - & - \\
\hline & & LM3L2A, LM3L2B & 0.002 & - & - \\
\hline & & LM3L3A, LM3L3B & 0.0002 & - & - \\
\hline & \multirow{4}{*}{ Short-term Creep } & LSRA, LSRB & - & $48,-$ & $3.37 f_{\mathrm{co}}^{\prime}\left(0.90 f_{\mathrm{cc}}^{\prime}\right)$ \\
\hline & & LSRC, LSRD & - & $48,-$ & $3.13 f^{\prime}{ }_{c o}\left(0.83 f_{c c}^{\prime}\right)$ \\
\hline & & LSRE, LSRF & - & 96,96 & $2.76 f_{\mathrm{co}}^{\prime}\left(0.73 f_{\mathrm{cc}}^{\prime}\right)$ \\
\hline & & LSRI (unconfined) & - & 48 & $0.85 f_{\mathrm{co}}^{\prime}$ \\
\hline \multirow{9}{*}{ Medium Strength } & \multirow{5}{*}{ Loading Rate } & $\begin{array}{l}\text { MM0L2A, MM0L2B, } \\
\text { MM0L2C }\end{array}$ & 0.002 & - & - \\
\hline & & MM3L0A, MM3L0B & 0.04 & - & - \\
\hline & & MM3L1A, MM3L1B & 0.02 & - & - \\
\hline & & MM3L2A, MM3L2B & 0.002 & - & - \\
\hline & & MM3L3A, MM3L3B & 0.0002 & - & - \\
\hline & \multirow{4}{*}{ Short-term Creep } & MSRA, MSRB, MSRH & - & $48,48,96$ & $0.89 f_{\mathrm{co}}^{\prime}\left(0.69 f_{\mathrm{cc}}^{\prime}\right)$ \\
\hline & & MSRI & - & 96 & $1.00 f_{\mathrm{co}}^{\prime}\left(0.77 f_{\mathrm{cc}}^{\prime}\right)$ \\
\hline & & MSRD, MSRE & - & 48,96 & $1.11 f_{\mathrm{co}}^{\prime}\left(0.86 f^{\prime}{ }_{\mathrm{cc}}\right)$ \\
\hline & & MSRC, MSRF & - & 48,96 & $1.20 f_{\mathrm{co}}^{\prime}\left(0.92 f_{\mathrm{cc}}^{\prime}\right)$ \\
\hline
\end{tabular}

${ }^{1} f_{\mathrm{cc}}^{\prime}$ is assumed as the average confined concrete strength of the LM3L2 and MM3L2 series specimens.

\subsection{Test Setup}

The specimens were tested under monotonic or sustained compressive loads by using a $5000-\mathrm{kN}$ capacity Instron Satec 1000RD universal testing machine (Norwood, MA, USA) that can be run under displacement or force control. Four linear variable displacement transducers (LVDTs) of the TML CDP-25 type with a gage length of $150 \mathrm{~mm}$ were attached to the specimen through a compressometer, to measure the average axial strains. The compressometer, which was compatible with the square cross-section of the prisms, was designed and manufactured particularly for this study. Lateral strains on the FRP surface at mid-height were measured by four surface strain gages (one on each side). The strain gages had a gage length of $60 \mathrm{~mm}$. For the measurement of loads, a TML CLP-100CMP type load cell with a capacity of $1000 \mathrm{kN}$ was used in parallel with the built-in load cell of Instron loading system. A specimen with the above-mentioned instrumentation can be seen in Figure 2b. Data acquisition was maintained via a 50-channel TML ASW-50C switch box (Tokyo Sokki Kenkyujo Co., Tokyo, Japan) and a TML TDS-303 data logger (Tokyo Sokki Kenkyujo Co., Tokyo, Japan). In short-term monotonic tests, data from the measuring devices was collected with random intervals. During the short-term creep tests, the displacement, strain and loading data were collected at every second automatically, until the target stress level 
was reached. Then, data collection continued at 20 -s intervals until the end of the sustained loading test. Short-term monotonic and residual capacity tests were performed by controlling the displacement; whereas, the short-term creep tests were controlled by force.

\subsection{Short-Term Monotonic Tests}

Short-term monotonic tests were carried out under different loading rates, which were defined as the ratio of cross-head displacement to specimen height. For this purpose, a total of 16 CFRP-confined concrete specimens from two different concrete strength groups (eight low-strength and eight medium-strength concrete specimens) were loaded under displacement control. As also indicated in Table 1, two identical specimens for each of the four different loading rates, 0.04, 0.02, 0.002 and $0.0002 \mathrm{strain} / \mathrm{min}$ (or $6.66 \times 10^{-4}, 3.33 \times 10^{-4}, 3.33 \times 10^{-5}$ and $6.66 \times 10^{-6} \mathrm{strain} / \mathrm{s}$ ), were used in the tests for the L0, L1, L2 and L3 loading series, respectively. According to the strain rate ranges given by Bischoff and Perry [9] for creep, static, earthquake, hard impact and blast loading conditions, the strain rate range investigated in this study extended the limits of the static loading case, since it was in between creep and earthquake loading strain rates. The intermediate loading rate, L2 (0.002 strain/min), was considered as the reference rate for determining the other loading rates, since it was ascertained as the average loading rate used in similar experiments. The major concern in deciding the maximum loading rate, L0 (0.04 strain/min), was the minimum reaction time of the measurement devices. The applied preloads for low-strength concrete samples and medium-strength concrete samples were $5 \mathrm{kN}$ and $7.5 \mathrm{kN}$, respectively. Unconfined concrete reference specimens were tested under a loading rate of $0.002 \mathrm{strain} / \mathrm{min}$ (L2).

\subsection{Short-Term Creep Tests}

Two confined specimens of low-strength concrete for each of the three different sustained axial stress levels were subjected to continuous axial load for targeted time durations (Table 1). For CFRP-confined low-strength concrete specimens, the sustained axial stress levels were $73 \%, 83 \%$ and $90 \%$ of the confined concrete strength $\left(f_{\mathrm{cc}}^{\prime}\right)$. These stress levels respectively corresponded to 2.76-, 3.13- and 3.37-times the unconfined concrete strength $\left(f_{\text {co }}^{\prime}\right)$. For low-strength concrete series, these reference $f_{\text {co }}^{\prime}$ and $f^{\prime}{ }_{\mathrm{cc}}$ values were obtained from monotonic loading tests (carried out at $0.002 \mathrm{strain} / \mathrm{min}$ loading rate) as 6.8 $\mathrm{MPa}$ and 25.6 $\mathrm{MPa}$, respectively. The single unconfined low-strength concrete prism (LSRI) was

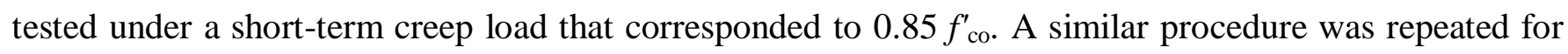
medium-strength concrete series. Eight specimens subjected to four different sustained axial stress levels were loaded for targeted time durations. For these specimens, the sustained axial stress levels were 69\%, $77 \%, 86 \%$ and $92 \%$ of the confined concrete strength $\left(f_{\mathrm{cc}}^{\prime}\right)$, or in other words, sustained axial stress levels corresponded to 0.89-, 1.0-, 1.1- and 1.2-times the unconfined concrete strength $\left(f_{\text {co }}^{\prime}\right)$, respectively. For medium-strength concrete series, the reference $f_{\text {co }}^{\prime}$ value was $31.2 \mathrm{MPa}$, and $f_{\text {cc }}^{\prime}$ was 40.5 MPa.

\subsection{Residual Strength Tests}

The CFRP-confined concrete prisms, which did not fail during the sustained loading phase, were tested under monotonic compression in order to assess their residual strengths. For each specimen, at the end of the targeted time duration of the sustained loading, the axial load was decreased to zero, and the 
specimens were kept unloaded for $30 \mathrm{~min}$. Then, they were reloaded monotonically with a loading rate of $0.002 \mathrm{strain} / \mathrm{min}$, until failure.

\section{Results and Discussions}

\subsection{Short-Term Monotonic Tests}

Among the low-strength concrete specimens, two unconfined ones (namely LM0L2A and LM0L2B), and among the medium-strength concrete specimens, three unconfined ones (namely MM0L2A, MM0L2B and MMOL2C), were tested under a 0.002 strain/min loading rate (L2 rate) as reference specimens. For low-strength concrete specimens, the average concrete strength and corresponding axial deformation values were $6.8 \mathrm{MPa}$ and $0.0028 \mathrm{~mm} / \mathrm{mm}$, respectively. For medium-strength concrete specimens, these values were $31.2 \mathrm{MPa}$ and $0.0025 \mathrm{~mm} / \mathrm{mm}$, respectively. A comparison with the CFRP-confined specimens (tested under the same 0.002 strain/min loading rate) points to a $350 \%$ strength and $1470 \%$ axial strain capacity enhancement for low-strength concrete and a $134 \%$ strength and $240 \%$ axial strain capacity enhancement for medium-strength concrete specimens.

The axial stress-strain relationships of CFRP-confined concrete prisms obtained for varying strain rates exhibit an apparent variation (Figure 3). Moreover, a definite difference between the curves of low-strength and medium-strength prisms can be observed. Low-strength specimens are characterized with a clear ascending branch after the unconfined concrete strength, whereas the post-peak curves of medium-strength specimens tend to descend after the peak stress. This result can be attributed to the difference between the effective confinement pressure/unconfined concrete strength ratios $\left(f_{1}^{\prime} / f^{\prime}{ }_{\text {co }}\right)$ of both specimen groups.

Figure 3. Stress-strain behavior of carbon fiber-reinforced polymer (CFRP)-confined specimens under different loading rates. (a) Low-strength concrete. (b) Medium-strength concrete.

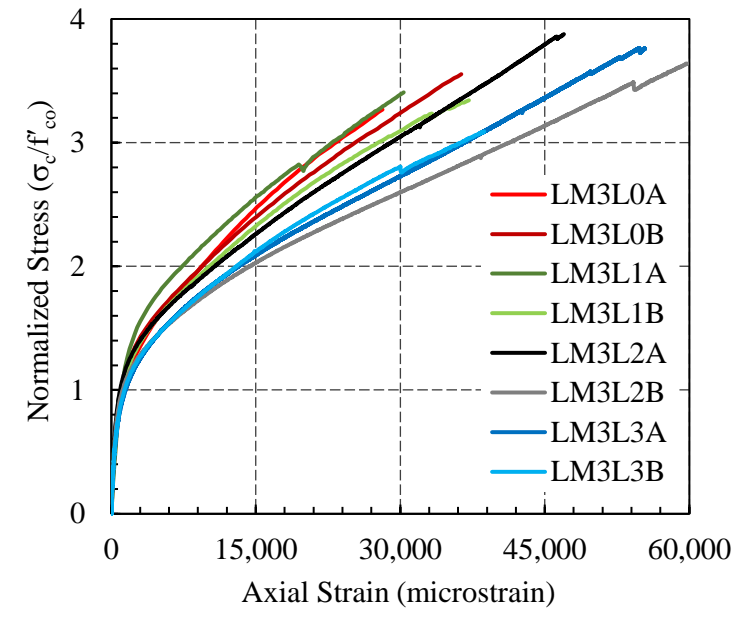

(a)

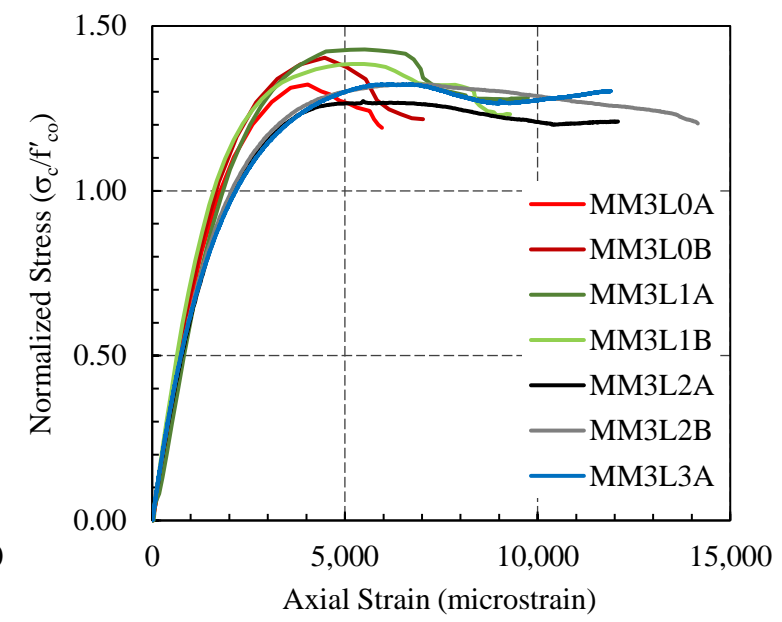

(b)

A closer look at the variation of normalized axial strength $\left(f^{\prime}{ }_{c o} f^{\prime}{ }_{c o}\right)$ with the utilized strain rates leads to a contrast between low- and medium-strength concrete specimens (Figure 4). In parallel with the test results presented by Demir et al. [10] for medium-strength CFRP-confined concrete cylinders, square cross-sectioned medium-strength prisms exhibit a tendency to have a higher strength with an increasing 
strain rate (Figure 4b). However, low-strength concrete prisms with CFRP confinement tend to have a lower strength enhancement (Figure 4a). For both low- and medium-strength cases, the variation of strength with the strain rate becomes significant between the L1 $\left(3.33 \times 10^{-4}\right.$ strain/s $)$ and L2 $\left(3.33 \times 10^{-5}\right.$ strain/s) strain rates.

Figure 4. The variation of strength enhancement. (a) Low strength. (b) Medium strength.

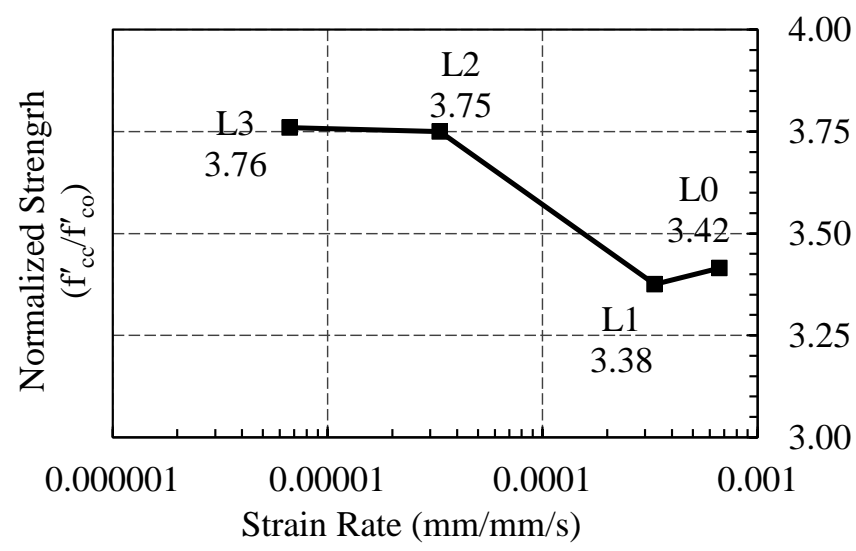

(a)

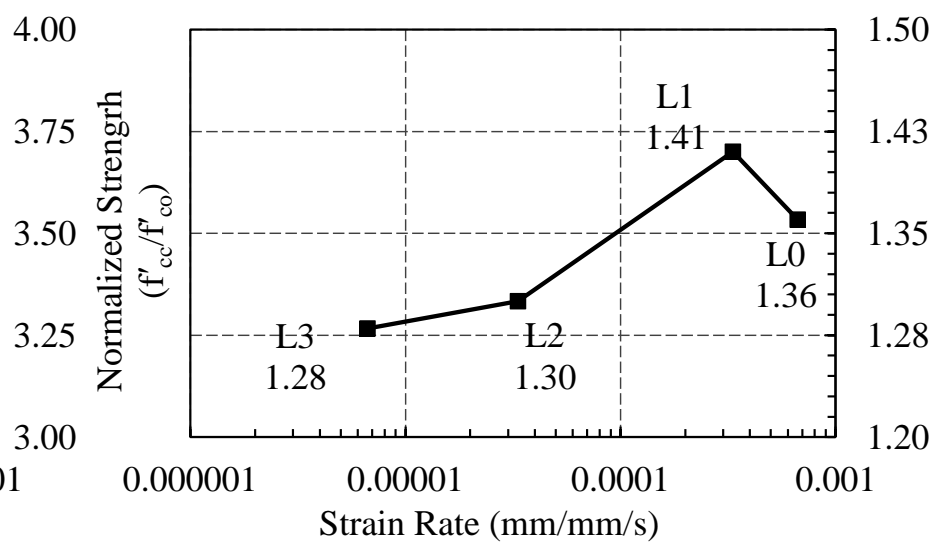

(b)

In the case of axial strain capacities normalized with axial strains corresponding to unconfined concrete strength $\left(\varepsilon_{\mathrm{cc}} / \varepsilon_{\mathrm{co}}\right)$, both groups of confined prisms exhibited a descending axial strain capacity for increasing strain rates (Figure 5). This observation is compatible with the results of previous tests performed on confined cylinders [10]. The order of normalized ultimate axial strains for low-strength prisms was much higher than that of medium-strength ones (between 11.5 and 19.7 for low-strength versus between 2.6 and 4.9 for medium-strength). The average lateral strains at failure of the specimens, which occurred due to the rupture of the CFRP sheets, were obtained by using the strain gauges at the mid-height of the specimens (Figure 6). Unlike the medium-strength cylinder specimens reported by Demir et al. [10], the rate of strain seems to have an effect on the rupture strains of rectangular prisms. Accordingly, rupture strains tend to decrease with increasing strain rates. The only exception to this observation is the lateral strain measured for the L3 strain rate $\left(6.66 \times 10^{-6} \mathrm{strain} / \mathrm{s}\right)$ of medium-strength concrete specimens. Although the behavior of CFRPs has been reported to be independent of the loading rate [20], the observations done here can be attributed to the uneven distribution of lateral strains around the square cross-section. 
Figure 5. The variation of the ultimate axial strain with the strain rate. (a) Low-strength concrete. (b) Medium-strength concrete.

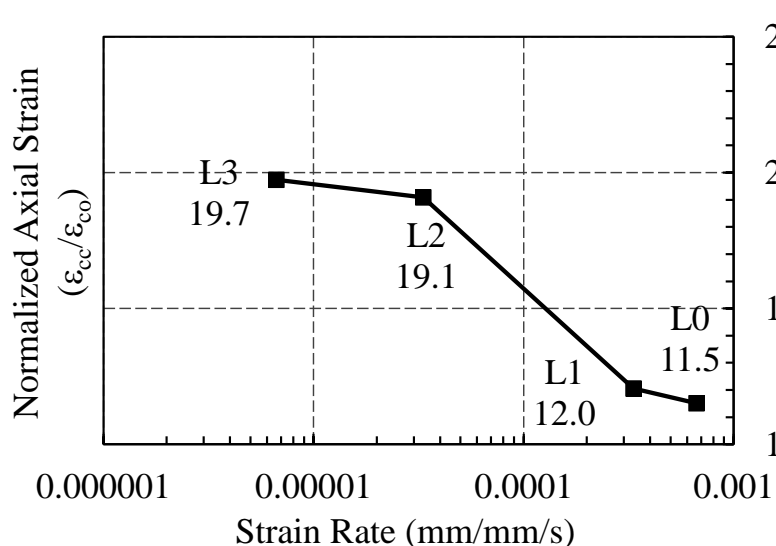

(a)
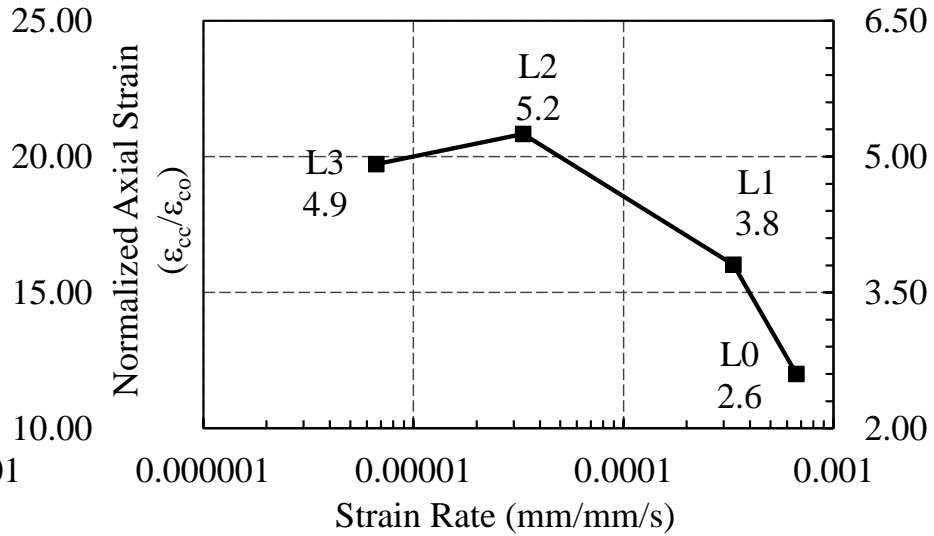

(b)

Figure 6. The variation of lateral strains at failure with strain rate (a) Low strength concrete. (b) Medium strength concrete.

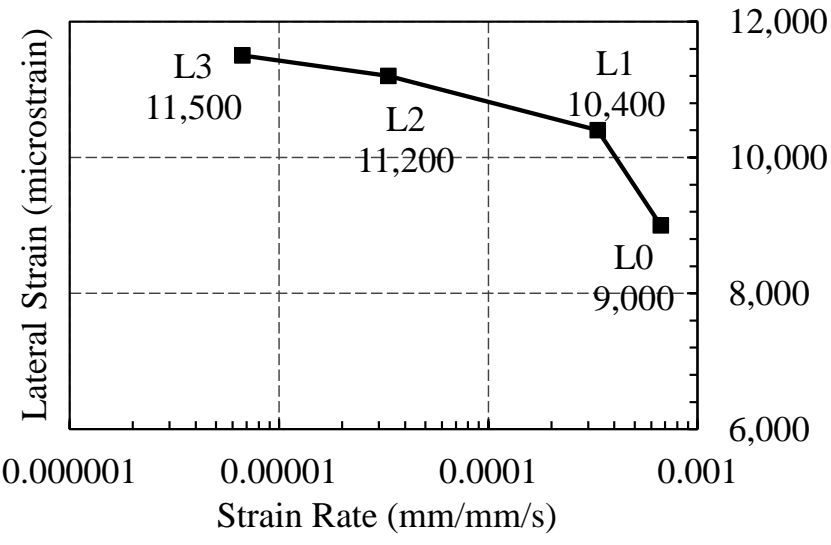

(a)

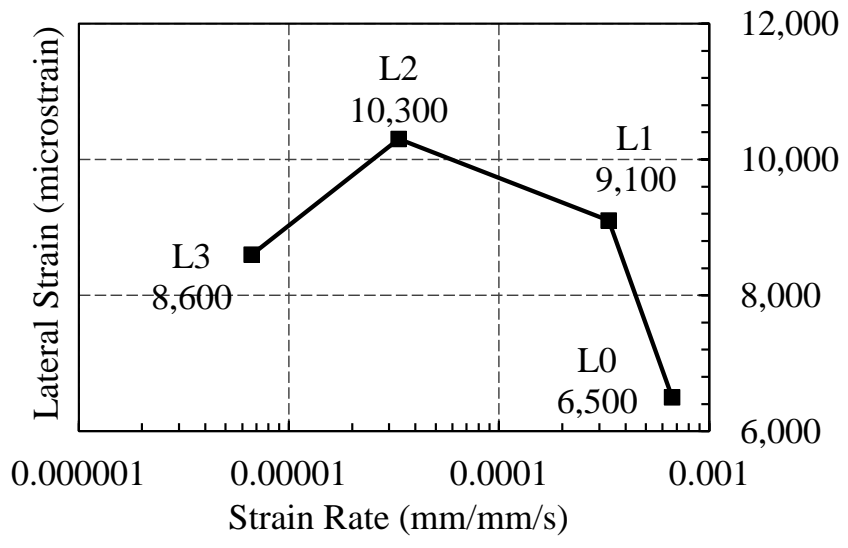

(b)

As also seen in Figure 3, the axial stress-strain relationships of CFRP-confined concrete prisms consist of two regions. In the first region, where FRP confinement is not fully activated yet, concrete dominates the behavior. Consequently, in parallel with the behavior of unconfined concrete, in the case of CFRP-jacketed cylinders, the slope of the first branch (elasticity modulus $E_{\mathrm{c}}$ ) tends to increase with increasing strain rates [10]. However, in the second region, the FRP wrap demonstrates a dominant behavior. Interestingly, in this study, in the case of low-strength concrete, the initial slope of the first branch $\left(E_{\mathrm{c}}\right)$ was not affected considerably by the change in strain rate (Figure 7a). In the case of medium-strength prisms, $E_{\mathrm{c}}$ exhibited a vague tendency to increase with the increasing strain rate (Figure 7b), whereas an apparent increase is reported by Demir et al. [10] for medium-strength cylinder specimens. 
Figure 7. The variation of the elasticity modulus. (a) Low strength. (b) Medium strength.

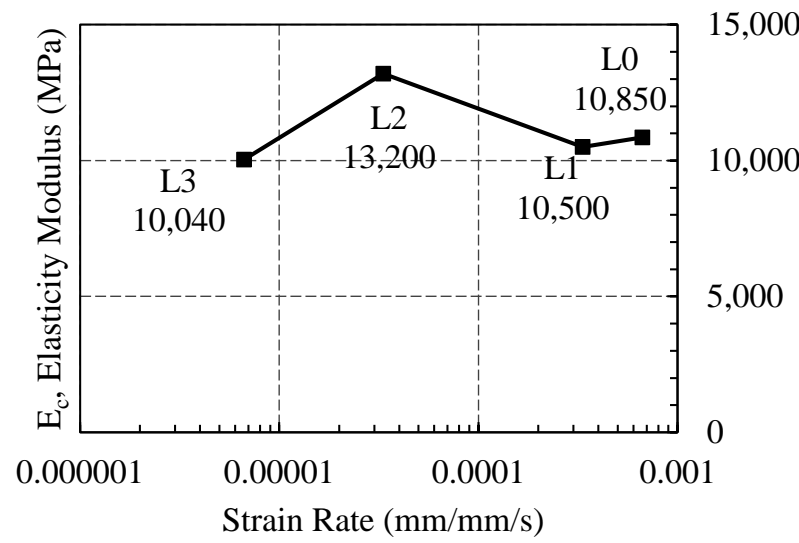

(a)

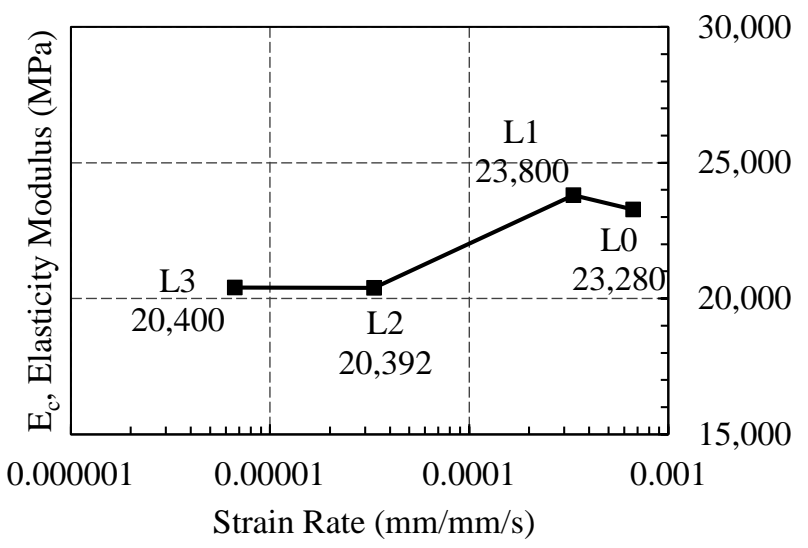

(b)

The post-peak curves of medium-strength specimens tend to descend after the peak stress (Figure $3 b$ ), mainly due to the relatively low amount of supplied confinement pressure to unconfined concrete strength ratio. Consequently, the slope of the second region (E2), which can be used for characterizing the post-peak axial stress-strain curves of FRP-confined concrete members, cannot be used for medium-strength specimens. However, it is interesting to note that, for medium-strength specimens, the post-peak descending branches obtained for different strain rates tend to get steeper for increased strain rates (Figure 3b). This observation is also noted by Mander et al. [21] for steel transverse reinforcement-confined concrete members. On the other hand, unlike the observations done by Demir et al. [10] for medium-strength cylinders, the slope of the second branch (E2) of CFRP-confined low-strength concrete prisms seems to be affected by the change in strain rates. Accordingly, the E2 slope increases for higher strain rates (Figure 8).

Figure 8. The variation of $E 2$ with the strain rate for low-strength concrete.

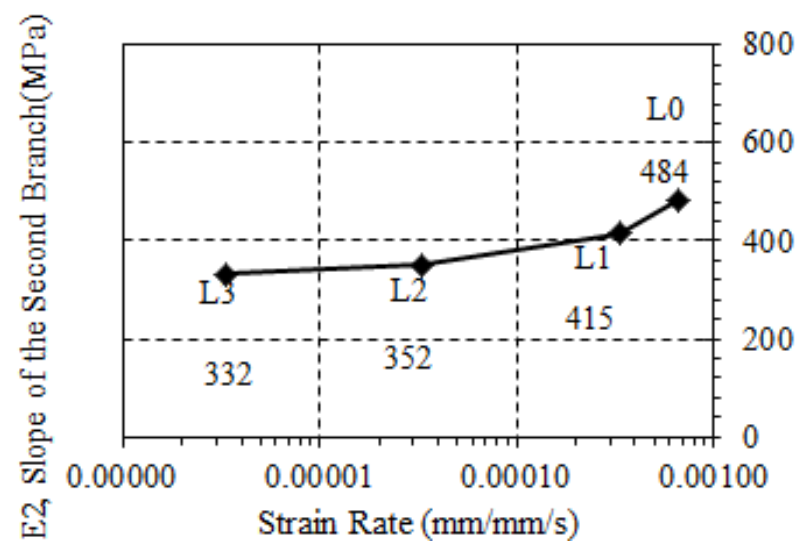

\subsection{Short-Term Creep Tests}

During sustained loading tests of low-strength concrete specimens, the behavior up to the target sustained stress levels (varying between $2.76 f^{\prime}{ }_{\text {co }}$ and $3.37 f^{\prime}{ }_{\text {co }}$ or $0.73 f^{\prime}{ }_{\mathrm{cc}}$ and $0.90 f^{\prime}{ }_{\mathrm{cc}}$ ) was identical to monotonic loading tests. However, one specimen from each of the specimen couples (LSRB and LSRD) that targeted $0.83 f^{\prime}{ }_{\mathrm{cc}}$ and $0.90 f^{\prime}{ }_{\mathrm{cc}}\left(3.13 f^{\prime}{ }_{\mathrm{co}}\right.$ and $\left.3.37 f^{\prime}{ }_{\mathrm{co}}\right)$ sustained stress levels unexpectedly failed in the 
vicinity of the target stress levels (Table 2). Similarly, the unconfined LSRI specimen failed three minutes after reaching the $0.85 f^{\prime}$ co stress. The premature failures of the specimens LSRB, LSRD and LSRI can be attributed to the possible variation in concrete compressive strength and workmanship errors, which might have led to non-uniform stress and strain distributions on the concrete and the external FRP jacket. In the case of specimens that could reach the target stress levels (the LSRA, LSRC, LSRE and LSRF specimens), the lateral strains initially exhibited a tendency to increase (Figure 9a). This increase was more remarkable for the LSRA and LSRC specimens that were subjected to higher stress levels than the LSRE and LSRF specimens. However, later on, the lateral strains were stabilized, and none of these four specimens reached failure during the short-term creep loading phase. It should be noted that the sudden increase in the lateral strain of the LSRA specimen occurred due to a load adjustment done during sustained loading (Figure 9a).

Figure 9. The variation of lateral strains with time. (a) Low-strength concrete.

(b) Medium-strength concrete.

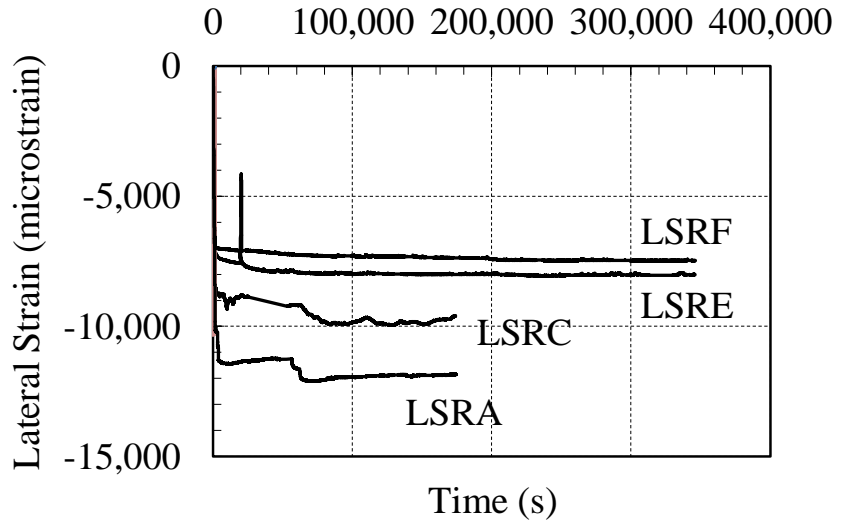

(a)

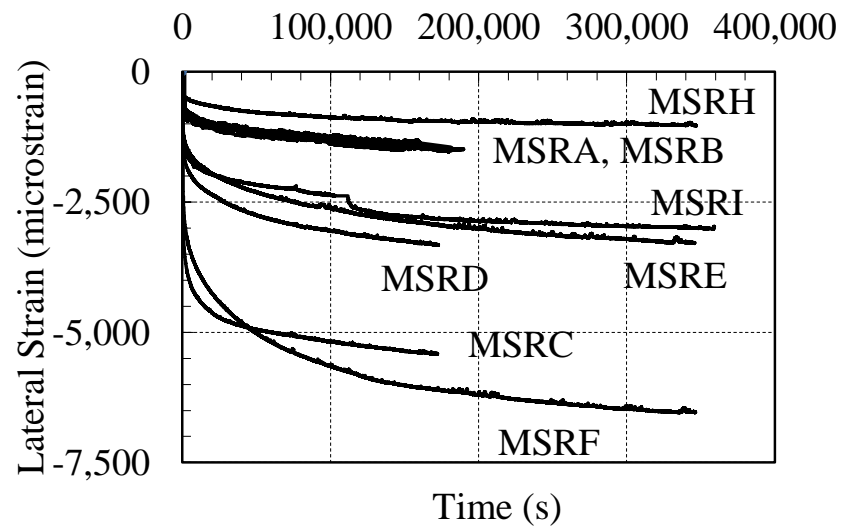

(b)

Table 2. Short-term creep tests.

\begin{tabular}{cccccc}
\hline $\begin{array}{c}\text { Concrete } \\
\text { Strength }\end{array}$ & Specimens & $\begin{array}{c}\text { Sustained Load } \\
\text { Duration (h) }\end{array}$ & $\begin{array}{c}\text { Sustained Axial } \\
\text { Stress Level }\end{array}$ & $\begin{array}{c}\text { Failure During } \\
\text { Sustained } \\
\text { Loading }\end{array}$ & $\begin{array}{c}\text { Likely to Fail } \\
\text { in Practical } \\
\text { Duration }\end{array}$ \\
\hline \multirow{3}{*}{ Low } & LSRA, LSRB & $48,-$ & $3.37 f_{\mathrm{co}}^{\prime}\left(0.90 f_{\mathrm{cc}}^{\prime}\right)$ & No, Yes & Yes \\
& LSRC, LSRD & $48,-$ & $3.13 f_{\mathrm{co}}^{\prime}\left(0.83 f_{\mathrm{cc}}^{\prime}\right)$ & No, Yes & Yes \\
& LSRE, LSRF & 96,96 & $2.76 f_{\mathrm{co}}^{\prime}\left(0.73 f_{\mathrm{cc}}^{\prime}\right)$ & No, No & No \\
& LSRI (no confinement) & 48 & $0.85 f_{\mathrm{co}}^{\prime}$ & Yes & Yes \\
\hline \multirow{2}{*}{ Medium } & MSRA, MSRB, MSRH & $48,48,96$ & $0.89 f_{\mathrm{co}}^{\prime}\left(0.69 f_{\mathrm{cc}}^{\prime}\right)$ & No, No, No & No \\
& MSRI & 96 & $1.00 f_{\mathrm{co}}^{\prime}\left(0.77 f_{\mathrm{cc}}^{\prime}\right)$ & No & Yes \\
& MSRD, MSRE & 48,96 & $1.11 f_{\mathrm{co}}^{\prime}\left(0.86 f_{\mathrm{cc}}^{\prime}\right)$ & No, No & Yes \\
& MSRC, MSRF & 48,96 & $1.20 f_{\mathrm{co}}^{\prime}\left(0.92 f_{\mathrm{cc}}^{\prime}\right)$ & No, No & Yes \\
\hline
\end{tabular}

In the case of CFRP-confined medium-strength prisms, none of the specimens failed during loading under the targeted sustained axial stress levels (varying between $0.89 f_{\text {co }}^{\prime}$ and $1.20 f_{\text {co }}^{\prime}$ or $0.69 f_{\text {cc }}^{\prime}$ and $0.92 f^{\prime}{ }_{\text {cc }}$ ) applied for designated loading durations (Table 2). This observation is parallel with the results indicated by Demir et al. [10] for medium-strength cylinders subjected to sustained axial stress levels 
varying between $0.90 f^{\prime}$ co and $1.46 f_{\text {co }}^{\prime}$ (or $0.52 f_{\text {cc }}^{\prime}$ and $0.85 f^{\prime}{ }_{\mathrm{cc}}$ ). The achieved lateral strains during the loading durations were less than the strains recorded for low-strength specimens (Figure 9b). The stabilization of lateral strains was not as apparent as the low-strength specimens, and the tendency for increase was similar to the medium-strength cylinder specimens [10].

In order to predict the life-time of the specimens subjected to sustained loading, a power type regression analysis was performed on the curves presented in Figure 9. Similar power type relationships for creep-time behavior were also reported by Bažant and Panula [22], American Concrete Institute (ACI) 209 [23] and Neville [24] for plain concrete and Naguib and Mirmiran [14,15] and Berthet et al. [12] for FRP-confined concrete. For medium-strength concrete specimens, the increase in the lateral strains was almost proportional with a $1 / 8$ power of time. However, for low-strength specimens, the lateral strains were proportional with approximately a $1 / 40$ power of time. A comparison of trend lines obtained for $48 \mathrm{~h}$ and $96 \mathrm{~h}$ loading for the same sustained stress level (i.e., a comparison of MSRA, MSRB and MSRH or MSRC and MSRF or MSRD and MSRE) led to similar power type relationships. During the analysis for the prediction of life-time under sustained loads, it has been assumed that the specimen fails when the trend line, generated by using lateral strain-time data, shown in Figure 9, reaches the FRP effective ultimate lateral strain (rupture strain). The FRP rupture strains were taken approximately as 11,000 microstrain for low-strength and 10,000 for medium-strength concrete prisms, which were determined to be the average rupture strains during the monotonic compression tests. The predictions for the likelihood of failure in a practical duration (i.e., durations up to 50 years) are presented in Table 2. The analysis of the lateral strain-time curves of low-strength LSRE and LSRF prisms with the lowest sustained stress level $\left(0.73 f_{\text {cc }}^{\prime}\right.$ or $2.76 f^{\prime}$ co $)$ showed that the specimens were unlikely to fail in a practical duration. However, other low-strength concrete specimens with $0.90 f_{\text {cc }}^{\prime}$ (LSRA) and $0.83 f_{\text {cc }}^{\prime}$ (LSRC) addressed service life durations that can be easily exceeded in actual conditions. These results are also supported with the premature failure of two other specimens (LSRB and LSRD) loaded to these stresses. In the case of medium-strength prisms, which had a considerably lower effective confinement pressure/unconfined concrete strength ratio $\left(f_{1}^{\prime} / f^{\prime}{ }_{\mathrm{co}}\right)$ than the low-strength specimens, the lateral strain-time curves exhibited a higher slope than the low-strength ones (Figure 9). Consequently, all specimens, except MSRA, MSRB and MSRH, which were subjected to a $0.89 f_{\text {co }}^{\prime}$ (or $0.69 f_{\text {cc }}^{\prime}$ ) sustained axial stress level, were found to fail in practical durations. A comparison with the medium-strength cylinders of Demir et al. [10] shows that a sustained stress level in the order of $f_{\text {co }}^{\prime}$ (or $0.77 f_{\text {cc }}^{\prime}$ ) may lead to failure in time for square cross-sectioned prisms, whereas cylinder specimens perform well under $1.12 f^{\prime}{ }_{\text {co }}$ (or $0.65 f^{\prime}$ cc) and $1.29 f^{\prime}{ }_{\text {co }}$ (or $0.75 f^{\prime}$ cc) stress levels.

It should be noted that the applied sustained stress levels were extremely high and quite unlikely for actual existing structures. However, extremely poor concrete and/or extreme loading conditions may cause unexpectedly high sustained axial stresses. In such cases, FRP confinement arises as an effective retrofitting technique for the prevention of potential damage due to the creep of existing concrete members. 


\subsection{Residual Capacity Tests}

Although some of the CFRP-confined concrete prisms failed under sustained axial loads, the remaining specimens were virtually undamaged after the short-term creep tests. In order to investigate the residual load and deformation capacities, sustained loads were removed, and the specimens were left unloaded for thirty minutes. Some strain regression occurred during this 30-min time interval. In the next step, the specimens were reloaded monotonically under a 0.002 strain/min loading rate until failure. The failure modes of the monotonic compression tests and residual capacity tests were similar. The sudden rupture of the external CFRP jacket generally initiated near the center of a side and extended along 1/3 of the specimen height. In a few cases, as also observed in the LSRA specimen, FRP rupture was close to one of the corners. In contrast with the observations done here, studies, such as Ilki et al. [3], Wang and $\mathrm{Wu}$ [25], Wu and Wei [26] and Rousakis and Karabinis [27], report the common FRP rupture location as corner regions of square and rectangular cross-sections. The difference may be attributed to the configuration of the pin supports of the compressometer. In this study, each arm of the compressometer was supported by two pins that were close to the corner regions of the specimens (locations marked in Figure 2b). Therefore, these pin supports may have affected the rupture path of FRP sheets in some cases. Typical views of the specimens after residual capacity tests can be seen in Figure 10.

Figure 10. Typical failure modes of residual capacity test specimens.
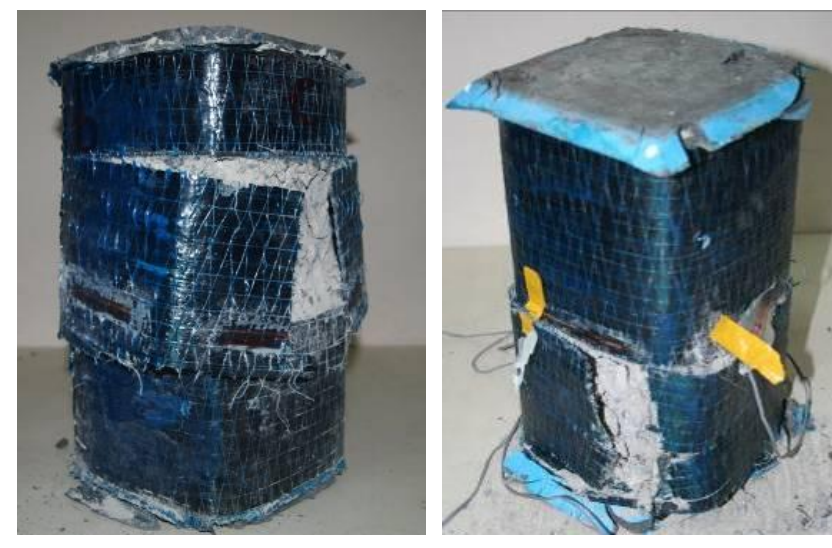

The axial stress-axial strain and axial stress-lateral strain curves obtained from residual capacity tests are presented in Figures 11-13. In these figures, it is also possible to compare the curves of monotonically-loaded, confined and unconfined prisms. Despite the utilized extremely high sustained stress levels and experienced axial and transverse deformations, sustained loading did not have negative effects on confined concrete strength and the ultimate deformation characteristics of low- and medium-strength concrete specimens. Moreover, all CFRP-confined low- and medium-strength prisms subjected to sustained loading experienced slightly higher strengths than the monotonically-loaded ones. In the case of medium-strength concrete, the strength enhancement was more pronounced for $96 \mathrm{~h}$ of sustained loading than the 48 hours of loading, as can be seen from Figures 12 and 13.

In many cases, short-term creep test specimens achieved slightly higher axial and lateral strain values than specimens tested under short-term monotonic loading, as also observed for cylindrical specimens [10]. This observation is clearer for lateral strains, indicated in Figure 6, for higher strain rates (such as L1 and L0 rates) versus the ultimate lateral strains shown in Figures $11 \mathrm{~b}$ and $12 \mathrm{~b}$ after sustained 
loading. This difference may probably be attributed to the intensification of the stresses under high strain rates, so that the internal redistribution of stresses is limited with respect to lower strain rates, where the more uniform propagation of microcracks permits a better internal stress redistribution. The internal redistribution capacity may become very decisive, particularly in the post-peak region, as also observed in the elastic rope-confined concrete tests performed by Rousakis [28] and Rousakis and Tourtouras [29].

Figure 11. Low-strength concrete residual capacity tests. (a) Axial stress-axial strain curves. (b) Axial stress-lateral strain curves.

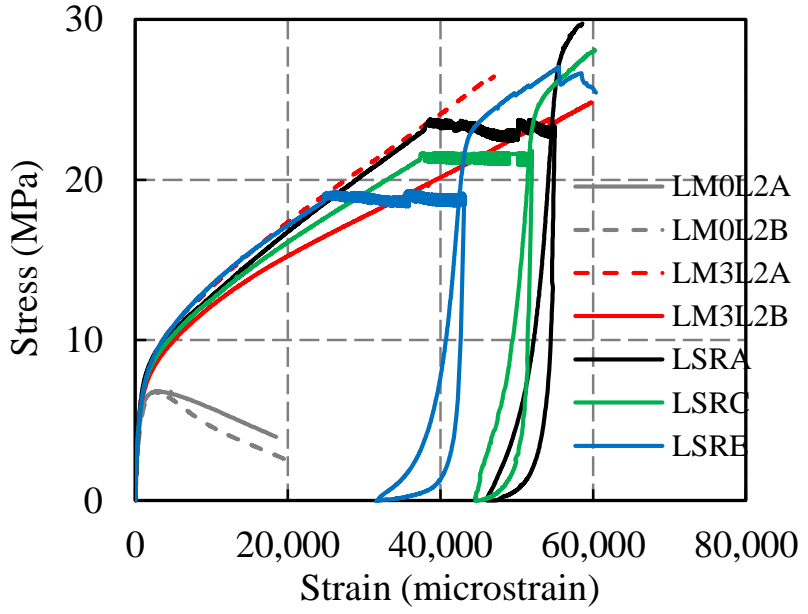

(a)

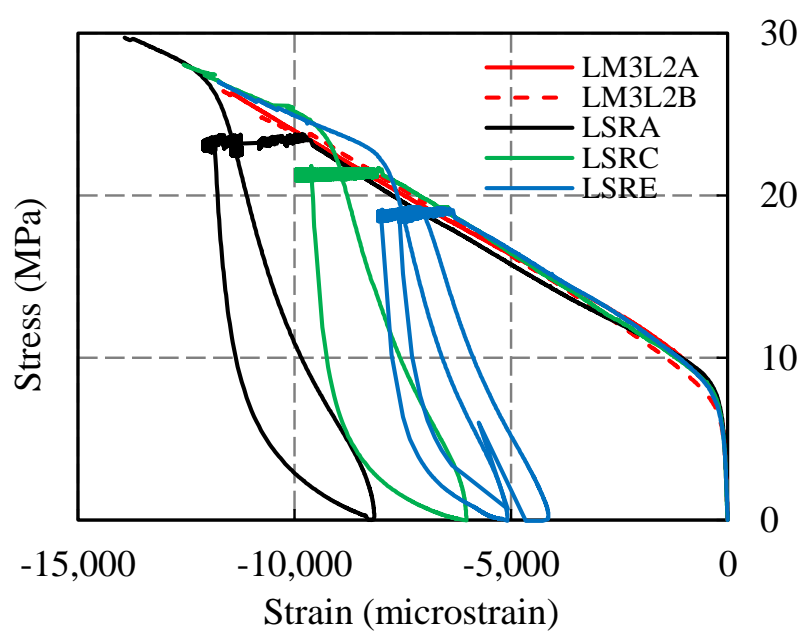

(b)

Figure 12. Medium-strength concrete residual capacity tests after $48 \mathrm{~h}$ of sustained loading. (a) Axial stress-axial strain curves. (b) Axial stress-lateral strain curves.

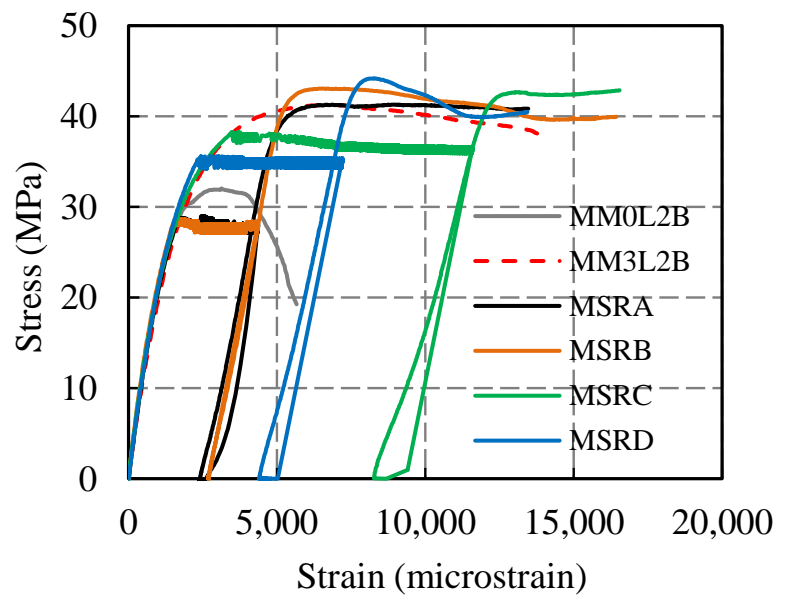

(a)

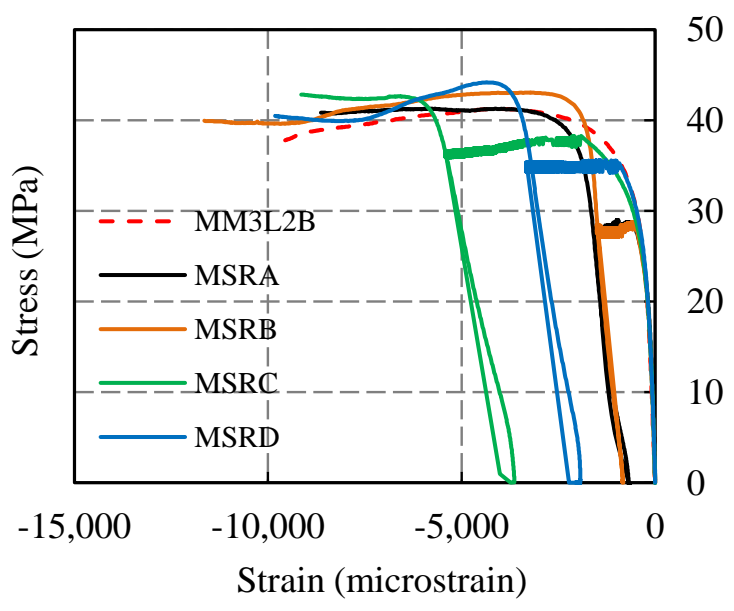

(b) 
Figure 13. Medium-strength concrete residual capacity tests after 96 h of sustained loading. (a) Axial stress-axial strain curves. (b) Axial stress-lateral strain curves.

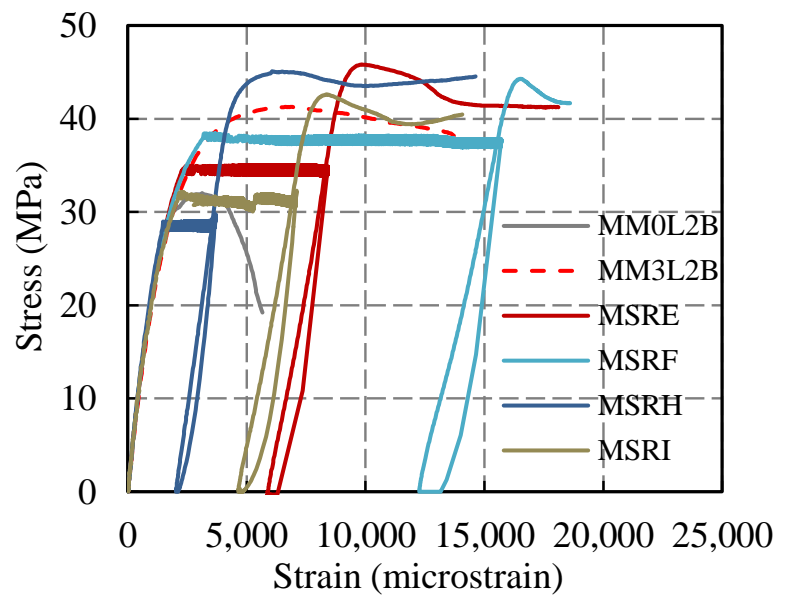

(a)

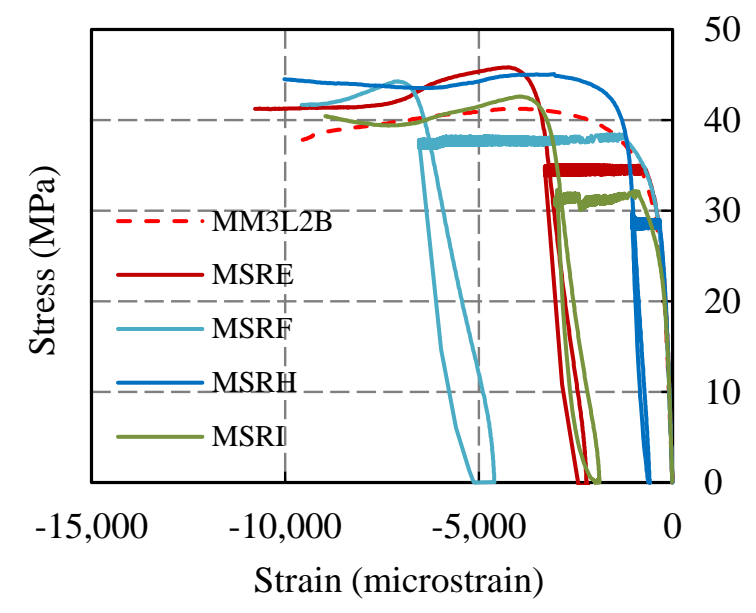

(b)

While the FRP confinement played an important role for the creep performance of the tested members, the efficiency of confinement was remarkably less than the efficiency reported by Demir et al. [10] for circular specimens. It is thought that this difference mainly stemmed from the distribution of the stresses in the cross-section. In the case of circular cross-sections, the distribution of the stresses is uniform, whereas in the case of square cross-sections, the distribution of stresses is quite irregular, due to concentrations at the corners. Therefore, the current study shows that it is important to approach the results of creep tests of FRP-confined circular specimens carefully before generalizing the obtained results for noncircular specimens.

Although the ultimate strain capacities of both low- and medium-strength prisms were not negatively affected by the sustained loading (Table 3), the residual strain capacities exhibited a dependence on the sustained strain level. Here, the residual strain capacity is defined as the difference between the ultimate axial strain reached during the residual capacity loading and the residual axial strain obtained after the unloading of sustained loading (strain at zero axial load). As presented in Table 3, for both concrete types, the residual strain capacities of all specimens corresponding to the same loading duration group decreased for increasing sustained stress levels (except the MSRE specimen). It should be noted that this reduction in residual axial strain capacity may negatively affect the seismic performance of CFRP-jacketed columns, which are somehow subjected to high sustained stress levels.

A Comparison of 48-h sustained loading with $96 \mathrm{~h}$ under similar stress levels shows that longer sustained loading may slightly increase the residual load capacity, as observed in Figure 14 (for MSRA, MSRB versus MSRH; MSRC versus MSRF and MSRD versus MSRF medium-strength prisms). Moreover, the ultimate axial strain capacities of specimens loaded under $96 \mathrm{~h}$ were higher than that of 48 h-loaded specimens. Despite the dependence of ultimate strain capacity to loading duration, no tendency could be observed for residual strain capacities obtained for 48- and 96-h loading durations (Table 3). 
Figure 14. Medium-strength concrete residual capacity tests: 48 h versus 96 h of loading.

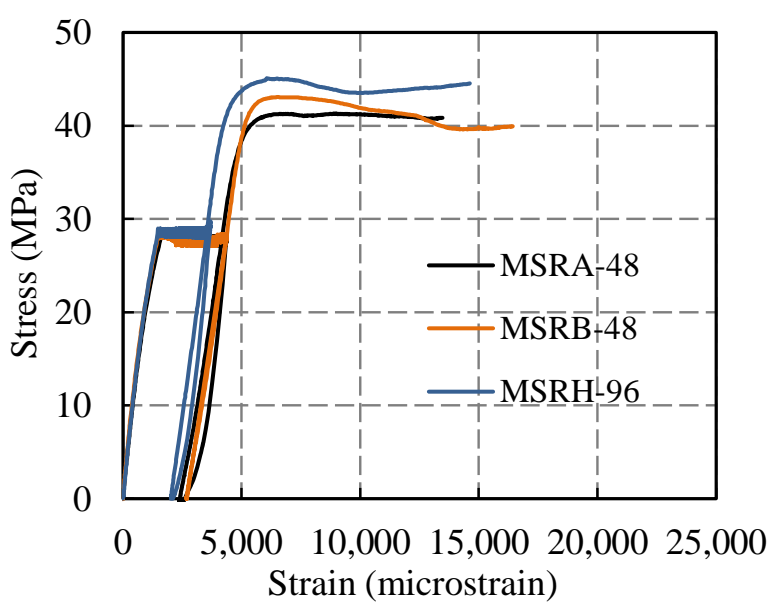

(a)

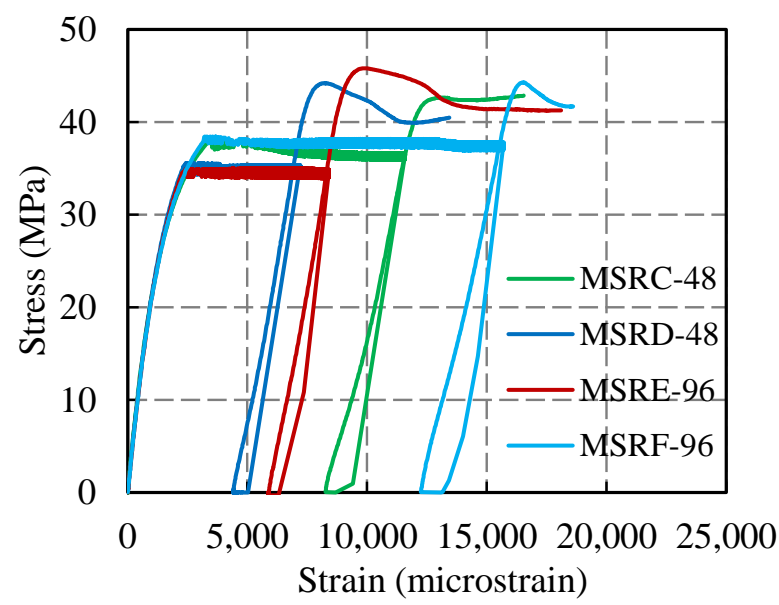

(b)

Table 3. Ultimate and residual strain capacities of short-term creep specimens.

\begin{tabular}{|c|c|c|c|c|c|}
\hline $\begin{array}{l}\text { Concrete } \\
\text { Strength }\end{array}$ & Specimens & $\begin{array}{l}\text { Sustained Load } \\
\text { Duration (h) }\end{array}$ & $\begin{array}{c}\text { Sustained Axial } \\
\text { Stress Level }\end{array}$ & $\begin{array}{l}\text { Ultimate Strain } \\
\text { Capacity } \\
\text { (microstrain) }\end{array}$ & $\begin{array}{c}\text { Residual Strain } \\
\text { Capacity (microstrain) }\end{array}$ \\
\hline \multirow{3}{*}{ Low } & LSRA & 48 & $3.37 f_{\mathrm{co}}^{\prime}\left(0.90 f_{\mathrm{cc}}^{\prime}\right)$ & 58,500 & 12,300 \\
\hline & LSRC & 48 & $3.13 f_{\mathrm{co}}^{\prime}\left(0.83 f_{\mathrm{cc}}^{\prime}\right)$ & 60,100 & 15,100 \\
\hline & LSRE, LSRF & 96,96 & $2.76 f_{\mathrm{co}}^{\prime}\left(0.73 f_{\mathrm{cc}}^{\prime}\right)$ & $60,300,55,200$ & $28,300,20,800$ \\
\hline \multirow{4}{*}{ Medium } & MSRA, MSRB, MSRH & $48,48,96$ & $0.89 f_{\mathrm{co}}^{\prime}\left(0.69 f_{\mathrm{cc}}^{\prime}\right)$ & $\begin{array}{c}13,400,16,400 \\
14,600\end{array}$ & $10,900,13,700,12,400$ \\
\hline & MSRI & 96 & $1.00 f_{\mathrm{co}}^{\prime}\left(0.77 f_{\mathrm{cc}}^{\prime}\right)$ & 14,000 & 9,410 \\
\hline & MSRD, MSRE & 48,96 & $1.11 \mathrm{f}_{\mathrm{co}}^{\prime}\left(0.86 f_{\mathrm{cc}}^{\prime}\right)$ & $13,400,18,100$ & $8,900,12,200$ \\
\hline & MSRC, MSRF & 48,96 & $1.20 f_{\mathrm{co}}^{\prime}\left(0.92 f_{\mathrm{cc}}^{\prime}\right)$ & $16,500,18,500$ & $8,200,6,300$ \\
\hline
\end{tabular}

\section{Conclusions}

In this study, the behavior of CFRP-confined prisms with square cross-sections were investigated under short-term monotonic and short-term creep loading. For this purpose, low- and medium-quality concrete specimens, confined with three plies of CFRP sheets, were prepared and tested under uniaxial compression. Short-term monotonic loading tests were carried out under different strain rates, and short-term creep tests were executed for different sustained stress levels. The specimens that did not fail during the short-term loading were, then, tested under monotonic compression for assessing the residual strength and deformation capacities. As a result of this research program, the following conclusions can be drawn:

- The stress-strain behavior of CFRP-confined concrete is affected by the change in the loading rate.

- As also observed for cylindrical specimens, the strength of CFRP-confined medium-strength concrete prisms increases with the increasing strain rate (about an 11\% difference between low and high strain rates). However, retrofitted, low-strength concrete specimens tend to have less 
strength enhancement with the increasing strain rate (about an $8 \%$ difference between low and high strain rates).

- Both low- and medium-strength concrete specimens exhibit higher strain capacities in the case of lower strain rates. The axial strain capacities at the lowest rate are approximately $70 \%$ and $90 \%$ higher than the strain capacities at the highest rate, for low- and medium-strength specimens, respectively.

- FRP rupture strains tend to decrease with increasing strain rates, particularly in the case of low-strength concrete (about a $28 \%$ difference for low-strength concrete).

- In the case of low-strength concrete, the initial slope of the first branch of stress-strain curves is not considerably affected by the change in the strain rate. In the case of medium-strength prisms, the initial slope exhibits a vague tendency to increase with the increasing strain rate (increases about $15 \%$ between the lowest and highest rates). However, a clear increase is reported by Demir et al. [10] for medium-strength cylindrical specimens.

- Unlike the previous observations made for medium strength cylindrical specimens, the slope of the second branch of axial stress-strain diagrams of CFRP-confined low-strength concrete prisms increases with increasing strain rates (about a 45\% increase). For medium-strength specimens, the post-peak descending branches obtained for different strain rates tend to get steeper for increased strain rates.

- CFRP confinement appears to be an effective retrofitting method against creep failures, even for sustained stress levels higher than the unconfined concrete strength (particularly for circular cross-sections, as was reported by the authors before [10]).

- For low- and medium-strength concrete prisms, sustained stress levels higher than $75 \%$ of the confined concrete strength (approximately corresponding to $2.76 f^{\prime}$ co and $f_{\text {co }}^{\prime}$ for low-strength and medium-strength prisms, respectively) may cause failure in a practical duration (i.e., during the service life of the structure).

- Power type relationships obtained for the variation of lateral strains under creep loads by time are similar for both the 48- and 96-h loading durations.

In the case of residual capacity tests performed after short-term creep loading under sustained axial loads, the following conclusions are reached:

- Sustained loading did not have negative effects on confined concrete strengths and the ultimate axial deformation capacities of low- and medium-strength concrete specimens.

- All CFRP-confined prisms subjected to sustained loading reached slightly higher strengths than the monotonically-loaded ones.

- Although the total axial deformation capacity was not negatively affected, the residual strain capacities of specimens corresponding to the same loading duration group (48 or $96 \mathrm{~h}$ ) decreased for increasing sustained stress levels.

- The increased duration of sustained loading led to slightly higher strength and ultimate strain values for medium-strength specimens.

- The efficiency of the confinement in the case of noncircular specimens was remarkably less than the efficiency reported by Demir et al. [10] for circular specimens. 
Further research on the investigated topic may include the effects of internal steel presence, existing pre-load and creep prior to FRP wrapping, FRP type, the FRP application procedure (i.e., textile reinforced mortar) and the presence of active confinement.

\section{Acknowledgments}

This study was supported by the BASF (Badische Anilin- and Soda-Fabrik) Turkey and ISTON (Istanbul Concrete Elements and Ready Mixed Concrete Factories Corporation) companies. The authors would like to thank Mehmet Ali Tasdemir for his continuous support. The authors wish to acknowledge the contributions of Nilgun Merve Caglar during the construction of the specimens.

\section{Author Contributions}

Cem Demir contributed to the analysis of the test data and writing of the paper. Aygul Kucukkapili was in charge of the production of the specimens and carried out the tests. Duygu Doyrangol contributed to the literature survey and analysis of the test data. Alper Ilki coordinated the study, interpreted the test results and contributed to the writing of the paper.

\section{Conflicts of Interest}

The authors declare no conflict of interest.

\section{References}

1. Parvin, A.; Brighton, D. FRP composites strengthening of concrete columns under various loading conditions. Polymers 2014, 6, 1040-1056.

2. Ilki, A.; Kumbasar, N.; Koc, V. Strength and deformability of low strength concrete confined by carbon fiber composite sheets. In Proceedings of the Pavement Mechanics Symposium at the 15th ASCE Engineering Mechanics Conference, New York, NY, USA, 4 June 2002.

3. Ilki, A.; Peker, O.; Karamuk, E.; Demir, C.; Kumbasar, N. FRP retrofit of low and medium strength circular and rectangular reinforced concrete columns. J. Mater. Civ. Eng. 2008, 20, 169-188.

4. Wu, Y.F.; Zhou, Y. Unified strength model based on Hoek-Brown failure criterion for circular and square concrete columns confined by FRP. J. Compos. Constr. 2010, 14, 175-184.

5. Karabinis, A.I.; Rousakis, T.C. Concrete confined by FRP material: A plasticity approach. Eng. Struct. 2002, 24, 923-932.

6. Mirmiran, A.; Shahawy, M.; Samaan, M.; EI Echary, H. Effect of column parameters on FRP-confined concrete. J. Compos. Constr. 1998, 2, 175-185.

7. Xiao, Y.; Wu, H. Compressive behavior of concrete confined by carbon fiber composite jackets. J. Mater. Civ. Eng. 2000, 12, 139-146.

8. Ozbakkaloglu, T.; Akın, E. Behavior of FRP-confined normal- and high-strength concrete under cyclic axial compression. J. Compos. Constr. 2012, 16, 451-463.

9. Bischoff, P.H.; Perry, S.H. Compressive behaviour of concrete at high strain rates. Mater. Struct. 1991, 24, 425-450. 
10. Demir, C.; Kolcu, K.; Ilki, A. Effects of loading rate and duration on axial behavior of concrete confined by fiber-reinforced polymer sheets. J. Compos. Constr. 2010, 14, 146-151.

11. Zhang, Y.; Su, S.; Su, J. The experimental research of carbon fiber confined concrete considering strain rate under uniaxial compression. Adv. Mater. Res. 2011, 163-167, 1485-1488.

12. Berthet, J.-F.; Ferrier, E.; Hamelin, P.; Al Chami, G.; Thériault, M.; Neale, K.W. Modelling of the creep behavior of FRP-confined short concrete columns under compressive loading. Mater. Struct. 2006, 39, 53-62.

13. Kaul, R.; Ravindrarajah, R.S.; Smith, S.T. Deformational behavior of FRP confined concrete under sustained compression. In Proceedings of the Third International Conference on FRP Composites in Civil Engineering, Miami, FL, USA, 13-15 December 2006; pp. 207-210.

14. Naguib, W.; Mirmiran, A. Time-dependent behavior of fiber-reinforced polymer confined concrete columns under axial loads. ACI Struct. J. 2002, 99, 142-148.

15. Naguib, W.; Mirmiran, A. Creep analysis of axially loaded fiber reinforced polymer-confined concrete columns. J. Eng. Mech. 2003, 129, 1308-1319.

16. Wang, Y.; Zhang, D. Creep-effect on mechanical behavior of concrete confined by FRP under axial compression. J. Eng. Mech. 2009, 135, 1315-1322.

17. Zhang, D.J.; Wang, Y.F.; Ma, Y.S. Compressive behaviour of FRP-confined square concrete columns after creep. Eng. Struct. 2010, 32, 1957-1963.

18. Erdil, B.; Akyuz, U.; Yaman, I.O. Mechanical behavior of CFRP confined low strength concretes subjected to simultaneous heating-cooling cycles and sustained loading. Mater. Struct. 2012, 45, 223-233.

19. Demir, C.; Aydogmus, A.; Ilki, A. Short term creep tests of low strength rectangular concrete members jacketed with carbon FRP sheets. In Proceedings of the APFIS 2012-The Third Asia-Pacific Conference on FRP in Structures, Sapporo, Japan, 2-4 February 2012.

20. Saiidi, M.S.; Johnson, R.; Maragakis, E.Z. Strain rate effects on strength of unidirectional FRP fabrics and bond to concrete. In Proceedings of the Third International Conference on FRP Composites in Civil Engineering, Miami, FL, USA, 13-15 December 2006; 79-82.

21. Mander, J.B.; Priestley, M.J.N.; Park, R. Theoretical stress-strain model for confined concrete. J. Struct. Eng. 1988, 114, 1804-1826.

22. Bažant, Z.P.; Panula, L. Practical prediction of time-dependent deformations of concrete. Mater. Struct. 1978, 11, 317-328.

23. Prediction of Creep, Shrinkage and Temperature Effects in Concrete Structures; Report No. ACI 209R-82; American Concrete Institute (ACI): Detroit, MI, USA, 1992.

24. Neville, A.M. Properties of Concrete; Pearson Education Limited: Essex, UK, 2003.

25. Wang, L.M.; Wu, Y.F. Effect of corner radius on the performance of CFRP-confined square concrete columns: Test. Eng. Struct. 2008, 30, 493-505.

26. Wu, Y.F.; Wei, Y.Y. Effect of cross-sectional aspect ratio on the strength of CFRP-confined rectangular concrete columns. Eng. Struct. 2010, 32, 32-45.

27. Rousakis, T.C.; Karabinis, A.I. Adequately FRP confined reinforced concrete columns under axial compressive monotonic or cyclic loading. Mater. Struct. 2012, 45, 957-975. 
28. Rousakis, T. Elastic fiber ropes of ultrahigh-extension capacity in strengthening of concrete through confinement. J. Mater. Civ. Eng. 2014, 26, 34-44.

29. Rousakis, T.C.; Tourtouras, I.S. RC columns of square section-Passive and active confinement with composite ropes. J. Compos. B Eng. 2014, 58, 573-581.

(C) 2014 by the authors; licensee MDPI, Basel, Switzerland. This article is an open access article distributed under the terms and conditions of the Creative Commons Attribution license (http://creativecommons.org/licenses/by/3.0/). 